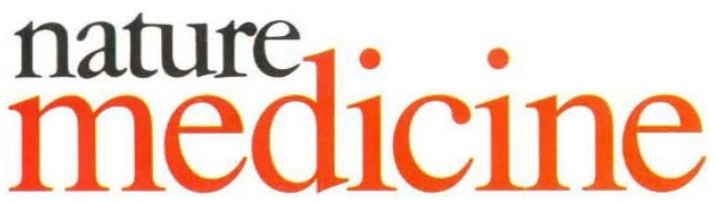

VOLUME 3 • NUMBER 8 • AUGUST1997

\title{
Research and the researcher
}

Last month saw the release of a report commissioned by the UK's Committee of ViceChancellors and Principals (CVCP), who represent the nation's universities, warning of impending difficulties for Britain's biomedical research community because of a perceived failing clinical academic research base (see News, page 821). The gist of the report is that MD's who wish to practice laboratorybased research and teaching, and therefore take the path of the clinical academic, are increasingly finding that their commitments to teaching and clinical responsibilities leave them with little opportunity to conduct research, and that over time this clinical research failing will make its presence felt in the form of a stuttering and eventually failing biomedical research engine. This demise, the report goes on to argue, will be hastened by the fact that the National Health Service (NHS), the country's main health care provider, is now under such pressure to make efficiencies that it can no longer countenance the distraction and expense of research, placing much of the country's medical research burden on the universities' clinical academic staff. The report proposes that the universities should address the problem by giving their clinical academic staffs a contract that guarantees them quality research time and that other measures should be taken to ensure that local circumstances allied to teaching and clinical duties will not erode that research time.

The report seems sensible. With tighter fiscal controls, the universities must squeeze more and more out of their staff. Clinical academics, who by definition should combine teaching, research and clinical duties, simply argue that if they are squeezed hard enough, the first thing to give under such pressure is their research. Usefully, the report exposes many discrepancies in how academic clinicians (and dentists) are paid and how their academic careers are structured, and suggests some remedies. However, where the report falls down is that it fails to present any convincing evidence that the system is indeed in crisis or likely to reach crisis soon, or that the perceived problem will have a dramatic effect on the country's biomedical research initiatives. The quoted statistics do not support the suggestion that clinical academics are leaving to go to (typically better paid) purely clinical posts - in fact, the number of clinical academics has risen over the past four years - nor does it present any evidence to show that even if academic clinicians started deserting what has traditionally been a high-profile and prestigious academic career path, the country's biomedical research system would slip into decline.

This is not to say that Britain's academic clinicians are not under pressure - they undoubtedly are - and perhaps this pressure is almost unavoidable given the tough demands of parallel careers in medicine, research and teaching. Indeed, commenting that academic clinicians "suffer the fate of any servant with two masters", the report's authors may even be tacitly recognizing the old adage "jack of all trades, master of none", a comment often made in private but rarely voiced publicly.

The report also seems unwilling to accept that the pressure that Britain's academic clinicians undoubtedly feel is much the same as that which most academic researchers around the world feel. Implicit throughout the report is the suggestion that the NHS and its clinical demands are putting an unreasonable pressure on academic clinicians (who are contracted to do clinical work) and that as a result, Britain's academic clinicians are in a unique bind. Yet a glance at other areas of the academic biomedical research community in the UK and beyond, suggests that the profession can inflict a tremendous pressure on those who choose to pursue it - pressure to secure funding, the pressure to publish (and to publish first) and the pressure associated with belonging to a profession that is severely undervalued, not so much in terms of recognition and respect but in terms of salary.

It is difficult to avoid the conclusion that the UK is simply experiencing growing pains as it learns to accept a market-driven research and health service environment to which it is has only recently become exposed. The market should however ensure that the best people will attract the necessary research grants to allow them to 'buy' research time, much as is seen in the US and was recently proposed by the Burroughs Wellcome Fund (see News, p. 821). And although in time the market may support fewer academic clinicians as demand places a greater emphasis on full-time researchers and full-time clinicians, it is likely that there will always be an important role for the $\mathrm{MD} / \mathrm{PhD}$ or academic clinician, to help advance experimental biomedical interventions from the laboratory to the bed side.

Perhaps the Vice-Chancellors and Principals can console themselves with the knowledge that at least they do not yet have to contend with "managed care" - a trend that is currently sweeping the US. According to a recent report from the Association of American Medical Colleges (J.A.M.A., July 16th, 1997) managed care is associated with an alarming recent drop in biomedical research funding in clinical departments at some of the country's medical schools. US states that have embraced the managed care approach to delivering health care are, the report states, seeing a fall in total National Institutes of Health $(\mathrm{NIH}$ - the country's primary source of biomedical research funding) research grant support, whereas those states with a relatively low managed care penetrance are seeing an increase in NIH research grant support. Although the report states that to date there is only evidence of an association between managed care and failing research funding, and admits that not much is known about the cause, it is sufficiently worrying to warrant immediate investigation. 